\title{
PEMANFAATAN PESAWAT TANPA AWAK UNTUK PEMETAAN DAN IDENTIFIKASI PENUTUPAN LAHAN PADA KAWASAN HUTAN PENDIDIKAN UNMUL
}

\author{
Muhammad Azizul Hakim ${ }^{1}$, Heni Emawati², Dwi Ery Mujahiddin ${ }^{3}$ \\ ${ }^{1}$ Kehutanan, Fakultas Pertanian, Universitas 17 Agustus 1945 Samarinda 75124, Indonesia. \\ Jl. Ir. H. Juanda No.80 75124 Samarinda, Indonesia. \\ ${ }^{2,3}$ Dosen Prodi Kehutanan, Fakultas Pertanian, Universitas 17 Agustus 1945 Samarinda \\ 75124, Indonesia. \\ E-Mail: aldipusamania11@gmail.com
}

\begin{abstract}
ABSTRAK
Pemanfaatan Pesawat Tanpa Awak Untuk Pemetaan Dan Identifikasi Penutupan Lahan Pada Kawasan Hutan Pendidikan UNMUL. Pada era modern ini pemotretan udara tidak hanya menggunakan pesawat berawak, namun dapat juga menggunakan pesawat tanpa awak atau UAV (Unamanned Aerial Vechicle) pesawat tanpa awak ini lebih dikenal dengan istilah drone yang saat ini dengan harga terjangkau, mudah didapatkan serta memiliki kemapuan melakukan pemotretan seperti pesawat berawak. Kelebihan utama dari drone, dibandingkan dengan pesawat berawak adalah bahwa drone dapat digunakan pada situasi dengan resiko tinggi, tanpa perlu membahayakan nyawa manusia, dan pada area yang tidak dapat diakses. Drone umumnya terbang pada ketinggian rendah sehingga foto yang dihasilkan terbebas dari awan.

Tujuan dari penelitian ini adalah Memetakan Kawasan Hutan Pendidikan Fakultas Kehutanan Unmul (HPFU) dengan menggunakan Pesawat Tanpa Awak atau UAV (Unmanned Aerial Vehicle). Mengidentifikasi dan mengetahui luasan masing-masing penutupan lahan pada Kawasan Hutan Pendidikan Fakultas Kehutanan Unmul (HPFU) dengan menggunakan citra foto udara. Penelitian ini dilakukan kurang lebih 2 bulan efektif.

Hutan Pendidikan Fakultas Kehutanan Unmul menjadi objek dilakukan penelitan dengan menggunakan Drone DJi Phantom 4 Pro V.2 dan menggunakan software pengolahan foto udara yaitu Agisoft Photoscan.

Hasil analisis data yaitu penggunaan lahan di HPFU didapatkan 12 jenis penggunaan lahan dan tutupan lahan. Hasil analisis spasial untuk luas dan masing-masing jenis penggunaan lahan terdiri dari Aren, Belukar rawa, Hutan sekunder, Kebun buah Naga, Kebun sawit, Lahan terbuka, Pemukiman, Pertanian Lahan Kering, Semak, Tambak ikan, Tambang dan Tubuh air.
\end{abstract}

Kata kunci : Pemetaan, Penutupan lahan, Pesawat tanpa awak.

\begin{abstract}
The utilization of the uncrewed aerial vehicle for Mapping and Identification of Land Closure in the Educational Forest Area of the Faculty of Forestry Unmul. In this modern era aerial photography is not only using manned aircraft, but can also use Uncrewed aerial vehicle or UAV (Unamanned Aerial Vechicle) Uncrewed aerial vehicle is better known as drones which are currently affordable, easy to obtain and have the ability to shoot like manned aircraft. The main advantage of drones, compared to manned aircraft is that drones can be used in high-risk situations, without the need to endanger human lives, and in inaccessible areas. Drones generally fly at low altitudes so that the resulting photo is free of clouds.

The purpose of this study is to map the Forest Education Area of the Unmul Forestry Faculty (HPFU) using Unmanned Aerial Vehicles (UAVS). Identify and know the the area of each land closure in the Forest Education Area of the Faculty of Forestry Unmul (HPFU) using the image of the aerial photo. This research was conducted approximately 2 months effectively.

Forest Education Faculty of Forestry Unmul was the object of research by using Drone DJi Phantom 4 Pro $V .2$ and using aerial photo processing software, namely Agisoft Photoscan. The results of data analysis is land use at HPFU obtained 12 types of land use and land cover. The results of spatial analysis for the area
\end{abstract}


and each type of land use consist of Aren, swamp shrub, secondary forest, dragon fruit garden, oil palm plantation, open land, settlement, dry land agriculture, shrubs, fishponds, mines and Body of water.

Key words : Land cover, Mapping, Unmanned aircraft.

\section{PENDAHULUAN}

$\begin{array}{crrr}\text { Teknologi modern } & \text { Sistem } \\ \text { Informasi Geografi } & \text { (SIG) }\end{array}$ penginderaan jauh (inderaja) dapat digunakan untuk mendapatkan data spasial digital dengan cepat dan akurat, sehingga mampu menjawab masalah kebutuhan informasi para pemangku kebijakan. Aplikasi teknologi inderaja yang multi konsep, dapat dimanfaatkan untuk memprediksi luas area. Teknologi inderaja yang banyak menggunakan citra satelit, yang digunakan saat ini, seringkali terkendala oleh tutupan awan, terutama pada saat musim hujan (Shofiyanti, 2011; Admoko, 2015; Julzarika, 2010; Prahasta, 2002; Lillesand dkk., 1993; Swistikayana, 2011).

Maka dari itu diperlukan adanya foto udara, agar hasil yang didapat relatif bersih dari awan, terbaru dan memiliki resolusi spasial yang tinggi. Namun demikian foto udara berawak (airborne remote sensing) membutuhkan biaya yang cukup mahal, jika di bandingkan dengan citra satelit, karena banyak hal yang diperlukan, seperti biaya operasional pesawat, izin penerbangan (misal untuk pesawat terbang, helikopter), biaya personil ke lapangan (pengambilan titik koordiant GCP ataupun pengoperasion pesawat), dan lain-lain.

Pada era modern ini pemotretan udara tidak hanya menggunakan pesawat berawak, namun dapat juga menggunakan Pesawat Tanpa Awak atau UAV (Unamanned Aerial Vechicle) pesawat tanpa awak ini lebih dikenal dengan istilah drone yang saat ini dengan harga terjangkau, mudah didapatkan serta memiliki kemapuan melakukan pemotretan seperti pesawat berawak.
Kelebihan utama dari drone, dibandingkan dengan pesawat berawak adalah bahwa drone dapat digunakan pada situasi dengan resiko tinggi, tanpa perlu membahayakan nyawa manusia, dan pada area yang tidak dapat diakses. Drone umumnya terbang pada ketinggian rendah sehingga foto yang dihasilkan terbebas dari awan.

Pesawat tanpa awak atau yang biasa disebut UAV (Unmanned Aerial Vehicle) telah lama dimanfaatkan dalam dunia militer, namun saat ini mulai digunakan untuk kepentingan sipil seperti pemantauan aktivitas manusia, survei keanekaragaman hayati, survei ekosistem sungai, pemantauan hutan berbasis masyarakat, dinamika penduduk dan penegakan hukum (Hodgson et al., 2016; Paneque-Galvez et al., 2014; Radiansyah, 2017).

Lokasi penelitian adalah Hutan Pendidikan Fakultas Kehutanan Unmul disingkat HPFU atau yang lebih dikenal sebagai Kebun Raya Unmul Samarinda (KRUS). HPFU merupakan salah satu diantara beberapa tempat wisata yang ada di kota Samarinda, ibukota Kalimantan timur yang terletak disebelah utara kota Samarinda. Untuk diketahui areal HPFU ini dulunya adalah HPH milik sebuah perusahaan, namun pada tahun 1974 perusahaan tersebut menyerahkan kawasan seluas 300 Ha Kepada Rektor Universitas Mulawarman untuk dikelola menjadi hutan konservasi atau kebun raya yang juga diperkuat oleh Gubernur dan Dinas Kehutanan Kalimantan Timur pada tahun 1997.

HPFU sebagai hutan pendidikan memiliki pengaruh yang besar terhadap mahasiswa sebagai objek studi pendidikan dan wadah praktek, sehingga HPFU seharusnya memiliki ketersediaan 
data baik spasial maupun informasi umum. Salah satu data yang perlu di miliki yaitu data spasial baik data vektor (titik, garis, polygon) maupun data raster (foto udara dan citra satelit). Salah satu cara untuk mendapatkan informasi spasial berupa foto udara adalah dengan menggunakan sebuah pesawat tanpa awak atau UAV (Unmanned Aerial Vehicle) fotogrametri. Dimana wahana yang dimaksud dapat mampu terbang sesuai perencanaan terbang (autopilot) dan dapat melakukan pemotretan foto udara.

Dari pembahasan di atas penelitian tentang proses pemetaan foto udara menggunakan drone di areal Hutan Pendidikan Fakultas Kehutanan Universitas Mulawarman, menjadi penting dan menarik untuk dilakukan dalam rangka mendapatkan data dasar pemetaan detail di kawasan ini yang diharapkan dapat berguna bagi kepentingan pengelolaan hutan dengan fungsi pendidikan. Tujuan penelitian adalah untuk memetakan Kawasan Hutan Pendidikan Fakultas Kehutanan Unmul (HPFU) dengan menggunakan Pesawat Tanpa Awak atau UAV (Unmanned Aerial Vehicle). Mengidentifikasi dan mengetahui luasan masing-masing tutupan lahan pada Kawasan Hutan Pendidikan Fakultas Kehutanan Unmul (HPFU) dengan menggunakan citra foto udara.

\section{METODA PENELITIAN}

\subsection{Tempat dan Waktu}

Penelitian ini dilaksanakan pada Kawasan Hutan Pendidikan Fakultas Kehutanan Unmul (HPFU) Samarinda seluas 295,88 Hektar berdasarkan Surat Keputusan Menteri Lingkungan Hidup dan Kehutanan Republik Indonesia Nomor : SK. 8109/MenLHK-
PKTL/KUH/PLA.2/11/2018. Pada Bulan September-Oktober 2019.

\subsection{Bahan dan Alat}

Adapun peralatan dan bahan yang digunakan dalam penelitian ini antara lain sebagai berikut :

Alat Penelitian:

a. Drone DJI Phantom 4 Pro V.2,

b. Aplikasi Dronedeploy dan DJI GO 4 merupakan software pengolahan foto dan pengambilan data dilapangan,

c. Aplikasi Avenza Maps,

d. Software Agisoft,

e. Seperangkat Komputer/Laptop yang dilengkapi dengan program Ms. Excel, Ms. Word dan program ArcGIS 10.6.

Bahan/data Penelitian

a. Peta Kawasan Hutan Pendidikan Fakultas Kehutanan Unmul (HPFU), Data Citra Satelit.

\subsection{Prosedur Penelitian}

a. Studi Pustaka

Studi pustaka ini meliputi kegiatan pengumpulan data mempelajari teori yang relevan dengan tema penelitian dan mengumpulkan data-data yang diperlukan untuk kegiatan penelitian, baik berupa data dari penelitian yang telah dilakukan, keterangan-keterangan lisan maupun masukan berbagai sumber lainnya.

b. Observasi Lapangan

Observasi lapangan bertujuan untuk mengetahui secara langsung keadaan dan kondisi lokasi penelitian yang akan dilakukan, yaitu dengan melakukan survei pendahuluan yang diharapkan dapat memperoleh informasi mendasar tentang kondisi dan areal tempat penelitian. sekaligus mempersiapkan bahan dan peralatan yang diperlukan selama penelitian.

c. Pembuatan Jalur Terbang Di Arcgis 


$\begin{array}{llll}\text { Pembuatan jalur terbang } & \text { (HPFU) yang dibagi menjadi 6 jalur } \\ \text { dilakukan diperangkat lunak ArcGIS } & \text { terbang. Desain jalur terbang di lokasi } \\ \text { dengan memasukan batas Hutan } & \text { penelitian tersaji pada gambar 1. }\end{array}$
Pendidikan Fakultas Kehutanan Unmul

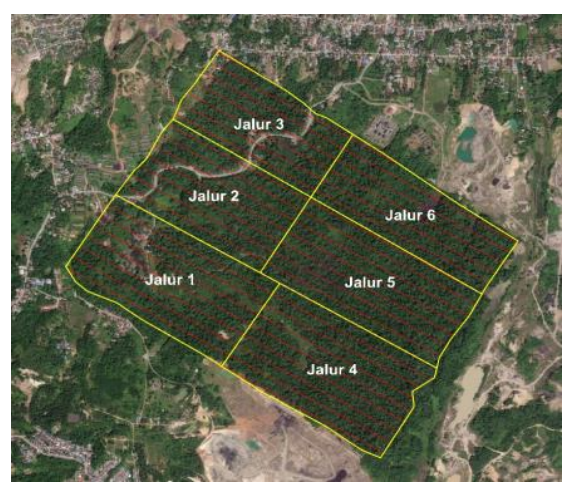

Gambar 1. Desain jalur terbang di Kawasan HPFU

d. Pengambilan Foto Udara
Menggunakan Drone
Pengambilan foto udara menggunakan Drone di bagi menjadi beberapa jalur terbang, dimana luasan areal yang diambil sebesar 295,88 ha. Sebelum ke aplikasi Dronedeploy buka aplikasi DJI GO 4 untuk melakukan kalibrasi Drone dan mengubah pengaturan pada Drone menjadi auto focus Tahapan pembuatan jalur terbang di Dronedeploy.

\section{e. Pengolahan Data}

Setelah pengambilan foto udara dengan menggunakan Drone maka dilakukan proses pengolahan data atau proses pembuatan Orthofoto. Pada proses ini digunakan prangkat lunak Agisoft Photoscan untuk pengolahan dari data berupa foto yang telah dihimpun untuk selanjutnya diproses menjadi peta.

\subsection{Analisis Data}

\section{a. Analisis Citra Foto Udara}

Analisis citra yang dilakukan pada penelitian ini adalah secara manual atau visual. Interpretasi dilakukan dengan melihat ciri/karakteristik obyek secara umum dengan mempertimbangkan unsur-unsur interpretasi seperti bentuk, ukuran, pola, bayangan, rona atau warna, tekstur, lokasi geografis dan asosiasi.

\section{b. Membangun kunci interpretasi}

Langkah selanjutnya adalah mengenali atau menafsir objek yang terdapat pada citra, untuk kemudian membangun kunci intepretasi. Dari tampilan citra kemudian diuraikan berdasarkan unsur-unsur interpretasi yang meliput : rona atau warna, ukuran, bentuk, tekstur, bayangan, pola, lokasi geografis dan asosiasi.

\section{c. Delinasi Penggunaan lahan}

Untuk mempermudah dalam pengelompokkan objek yang akan disajikan kedalam peta sesuai dengan tema interpretasinya dibatasi dengan pengklasifikasian objek atau fenomena sesuai klasifikasi ini disebut dengan delinasi hasil, kemudian diproses dengan menggunakan ArcGis 10.6 untuk membuat poligon dengan atribut pengunaan lahan. 
d. Pengecekan sampel di Lapangan Ground Check

Pengambilan titik lapangan dilakukan dengan menggunakan Smartphone yang dilengkapi dengan aplikasi Avenza maps berdasarkan titik yang sudah ditelah dibuat melalui aplikasi Arcmap. Ground check juga digunakan sebagai metode untuk menilai keakurasian interpretasi yang telah dilakukan.

\section{HASIL PENELITIAN DAN PEMBAHASAN}

\subsection{Keadaan Umum Lokasi Penelitian}

Letak dan Luas Lokasi Penelitian

Hutan Pendidikan Fakultas

Kehutanan Universitas Mulawaman secara geografis terletak diantara $117^{\circ} 12^{\prime} 15,3^{\prime \prime}$ - 117013'35,786" BT dan antara $0^{\circ} 26^{\prime} 17,435^{\prime \prime}$ - $0^{\circ} 27^{\prime} 32,769^{\prime \prime}$ LS.

Secara administrasi pemerintahan terletak dalam 2 wilayah administrasi kelurahan yaitu Kelurahan Tanah Merah Kecamatan Samarinda Utara dan Kelurahan Mugirejo Kecamatan Sungai Pinang, Kota Samarinda. Secara hidrologis wilayah Hutan Pendidikan Fakultas Kehutanan Universitas Mulawarman terletak pada bagian hulu Sub Das Karang Mumus yang mengalir Sungai Mahakam.

Luas wilayah Hutan Pendidikan

Fakultas Kehutanan Universitas

Mulawarman berdasarkan Surat Keputusan Menteri Kehutanan dan Perkebunan No. 406/Kpts-II/99 tanggal 14 Juni 1999 tentang penetapan fungsi Kawasan Hutan Lempake sebagai Kawasan Tetap dan fungsi Hutan Pendidikan Fakultas Kehutanan Universitas Mulawarman luasnya 299,03 Ha. Berdasarkan penetapan wilayah KPHL Dan KPHP Provinsi Kalimantan Timur Nomor : SK.647/Menhut-II/2011, Tanggal 1 Desember 2011 yaitu seluas 289 Ha. Semetara itu menurut Surat
Keputusan Menteri Lingkungan Hidup dan Kehutanan Nomor : SK. 8109/MenLHK-

PKTL/KUH/PLA.2/11/2018 Tentang Peta Perkembangan Pengukuhan Kawasan Hutan Provinsi Kalimantan Timur Sampai Dengan Tahun 2017 luas Hutan Pendidikan Fakultas Kehutanan Universitas Mulawarman adalah 295,88 Ha. Berdasarkan peruntukan Lahan Kawasan Hutan Pendidikan Fakultas Kehutanan Universitas Mulawarman dibagi menjadi 3 zona yaitu zona koleksi dengan luas $100 \mathrm{Ha}$, zona rekreasi seluas $65 \mathrm{Ha}$, dan zona konservasi seluas 135 Ha.

Hutan Pendidikan Fakultas Kehutanan Universitas Mulawarman merupakan kawasan yang masih bernuansa alami dengan habitat hutan hujan tropis dataran rendah (Lowland Tropical Rainforest), yang terletak pada ketinggian \pm 50 meter dari permukaan laut dengan kelembaban udara 80-90\% dan curah hujan bulanan rata-rata 211,5 $\mathrm{mm}$.

Unsur Cuaca/Iklim Lokasi Penelitian Karyati (2016) melaporkan berdasarkan data yang diperoleh dari Badan Meteorologi Klimatologi dan Geofisika (BMKG) selama 7 tahun terakhir (2008-2014), curah hujan bulanan $211,5 \mathrm{~mm}$, suhu udara $27,4^{\circ} \mathrm{C}$, kelembaban udara relatif $82,2 \%$, dan lama penyinaran rata-rata adalah 41,8 jam.

Iklim Kota Samarinda diklasifikasikan menjadi tipe iklim A, berdasarkan sistem klasifikasi SchimdtFerguson (1951) dengan nilai Q (Quotient) sebesar 0,048 yang merupakan daerah sangat lembab dengan vegetasi hutan hujan tropis (Karyati, 2016).

Geologi dan Tanah Kondisi geologi kawasan Hutan Pendidikan Fakultas Kehutanan 
Universitas Mulawarman tersusun oleh batuan-batuan quaternary dan miocenem serta oleh tanah alluvial pada periode Kuarter, sedangkan jenis tanahnya tersusun oleh tanah pasiran atau geluh lempung yang disertai dengan endapan batuan kapur dari zaman myosin yang dapat diklasifikasikan ke dalam tanah podsolik merah dan podsolik kuning (Karyati, 2017).

\section{Hidrologi}

Hutan Pendidikan Fakultas

Kehutanan Universitas Mulawarman terletak di bagian tengah hulu sub DAS Karang Mumus yang mengakibatkan cabang-cabang sungai Karang Mumus yang berada di dalam kawasan HPFU tidak terpengaruh oleh pasang surut aliran sungai sehingga aliran airnya terutama berasal dari curah hujan yang turun di kawasan tersebut yang selanjutnya mengalir ke arah selatan menuju Sungai Mahakam.

\section{Aksebilitas dan Infrastuktur}

Ketersediaan infrastruktur jalan merupakan input penting dalam operasional pengelolaan hutan di lapangan, hal ini berkaitan dengan "tingkat keterjangkauan kawasan hutan (tingkat aksebilitas). Selanjutnya tingkat aksebilitas akan mempengaruhi intensitas pengelolaan, utamanya fungsi "pengawasan". Fungsi ini yang nantinya akan menjadi fungsi penting yang harus diperankan oleh Hutan Pendidikan Fakultas Kehutanan Universitas Mulawarman dalam pengelolaan wilayah kelola yang luas tersebut.

Di areal yang dekat dengan Hutan Pendidikan Fakultas Kehutanan Universitas Mulawarman Titik api yang di dapatkan pada kelurahan tanah merah dengan di dominasi pada areal dengan jarak dari jalan kurang dari $700 \mathrm{~m}$, hal ini membuktikan areal yang dekat dengan akses jalan memiliki potensi terjadi kebakaran dibandingkan dengan areal yang jauh dari jaringan jalan.

\subsection{Hasil Pembentukan Orthofoto}

Pengolahan foto-foto menjadi orthophoto dilakukan dengan menggunakan Agisoft Photoscan. Dari hasil 949 pemotretan foto udara pada Kawasan HPFU, Untuk perangkat lunak Agisoft Photoscan waktu untuk pembentukan orthofoto diperlukan waktu \pm 2 jam pada tingkat akurasi medium. Hasil pengujian akurasi yang dilakukan menunjukkan persentase akurasi mencapai 95\%, sehingga data dari kendaraan udara nirawak dapat dimanfaatkan untuk pemetaan suatu wilayah (Bintoro dkk. 2018). Hasil penelitian menunjukkan metode dengan menggunakan informasi tekstur dalam klasifikasi berbasis obyek memiliki hasil akurasi yang jauh lebih baik mencapai $95.22 \%$ atau berbeda $17.5 \%$ dibanding metode konvensional yang mencapai akurasi $77.71 \%$ (Sari dan Kushardono, 2014).

Pembentukan orthophoto menggunakan Agisoft Photoscan menghasilkan otrhofoto yang cukup baik. kecerahan serta tekstur warna yang dihasilkan cukup baik. Perkembangan permintaan informasi geospasial pada suatu kawasan dengan berbagai bidang akan berdampak pada perkembangan metode dalam kegiatan foto udara. Teknologi canggih seperti kamera dan drone membuat pekerjaan relatif cepat dan dengan resolusi foto yang tinggi (Pranata dkk. 2020). foto udara didapatkan nilai overall accuracy sebesar $83,530 \%$. Sedangkan LiDAR hanya sebesar $64,595 \%$ untuk nilai overall accuracy (Marwati dkk. 2018). Pemetaan menggunakan metode klasifikasi vegetasi dan tutupan lahan berbasis obyek berdasarkan informasi nilai indeks vegetasi (NDVI) dan klasifikasi nearest neigh bour pada training samples yang 
telah ditentukan. Hasil dari penelitian ini menunjukkan metode klasifikasi dengan Object-Based Image Analysis (OBIA) memiliki keluaran peta klasifikasi yang cukup detil (sitompul dkk. 2019). Produk akhir dari sistem ini efektif untuk menghasilkan dan memutakhirkan peta dasar lahan, mengevaluasi dan memeriksa perubahan konversi fungsi lahan serta memfasilitasi layanan digital. Ketersediaan perangkat lunak open source secara efisien mengekstrak dan menggabungkan produk pemetaan terestrial dan fotogrametri secara real time dan memiliki peluang untuk mewujudkan kadaster multiguna (Junarto dkk. 2020). Hasil pembentukan Orthophoto dengan Agisoft dapat dilihat pada gambar 2 dan hasil Pemotongan batas HPFU menggunakan Arcgis pada gambar 3.

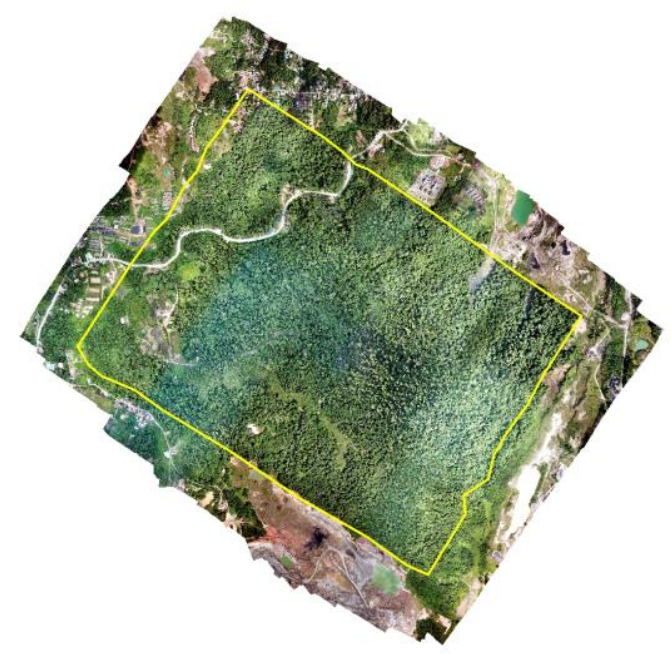

Gambar 2. Orthophoto Hasil Pengolahan Agisoft Photoscan

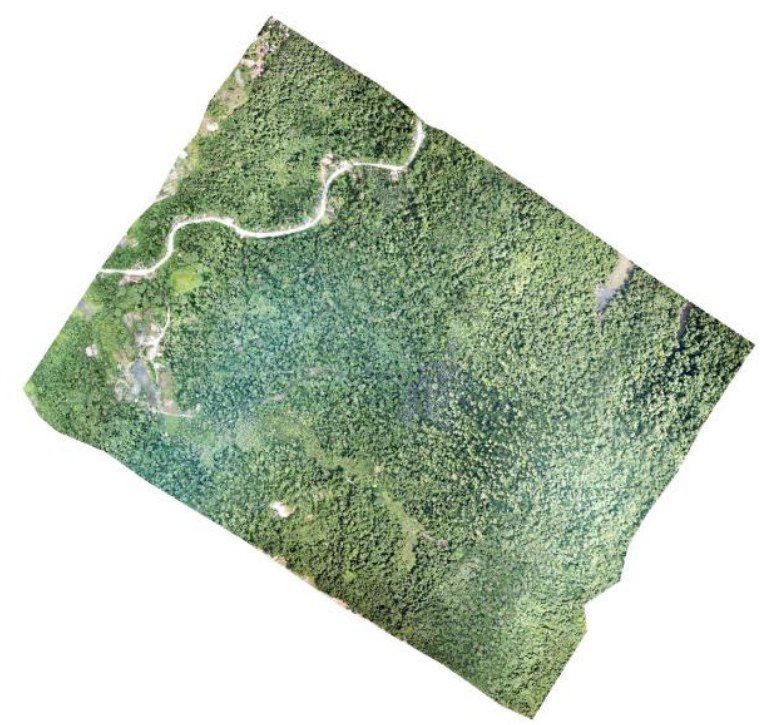

Gambar 3. Hasil Pemotongan Batas HPFU 


\subsection{Hasil Analisis Penggunaan Lahan Pada Kawasan HPFU}

Berdasarkan hasil interpretasi melalui foto udara pada kawasan HPFU untuk penggunaan lahan didapatkan 12 jenis penggunaan lahan dan tutupan lahan. Hasil analisis spasial untuk luas dan masing-masing jenis penggunaan lahan terdiri dari Aren, Belukar rawa, Hutan sekunder, Kebun buah Naga, Kebun sawit, Lahan terbuka, Pemukiman, Pertanian Lahan Kering, Semak, Tambak ikan, Tambang dan Tubuh air yang disajikan pada tabel 1 .

Tabel 1. Jenis dan Luas penggunaan lahan berdasarkan foto udara

\begin{tabular}{lllr}
\hline No. & Jenis Vegetasi dan Tutupan lahan & Luas (Ha) & Persen $(\%)$ \\
\hline 1 & Aren & 4,13 & 1,40 \\
2 & Belukar Rawa & 9,62 & 3,25 \\
3 & Hutan Sekunder & 269,36 & 91,04 \\
4 & Kebun Buah Naga & 0,26 & 0,09 \\
5 & Kebun Sawit & 1,41 & 0,48 \\
6 & Lahan Terbuka & 5,75 & 1,93 \\
7 & Pemukiman & 0,64 & 0,22 \\
8 & Pertanian Lahan Kering & 0,23 & 0,08 \\
9 & Semak & 0,98 & 0,33 \\
10 & Tambak Ikan & 0,3 & 0,10 \\
11 & Tambang & 0,68 & 0,23 \\
12 & Tubuh Air & 2,51 & 0,85 \\
\hline Total & & $\mathbf{2 9 5 , 8 8}$ & $\mathbf{1 0 0 , 0 0}$ \\
\hline
\end{tabular}

Dari perhitungan diatas diketahui (>90 \%) Kawasan HPFU terdiri dari Hutan Sekunder dengan luas 269,36 ha dari Total keseluruhan 295,88 ha, disusul oleh Belukar rawa 9,62 ha, Lahan terbuka 5,75 ha, Aren 4,13 ha, Tubuh Air 2,51 ha, Kebun Sawit 1,41 ha, Semak 0,98 ha,
Tambang 0,68, Pemukiman 0,64 ha, Tambak Ikan 0,30 ha, Kebun Buah Naga 0,26 ha dan Pertanian Lahan Kering 0,23 ha. Hasil delinasi penggunaan lahan dapat dilihat pada peta Penutupan lahan pada kawasan HPFU yang disajikan pada gambar 4. 


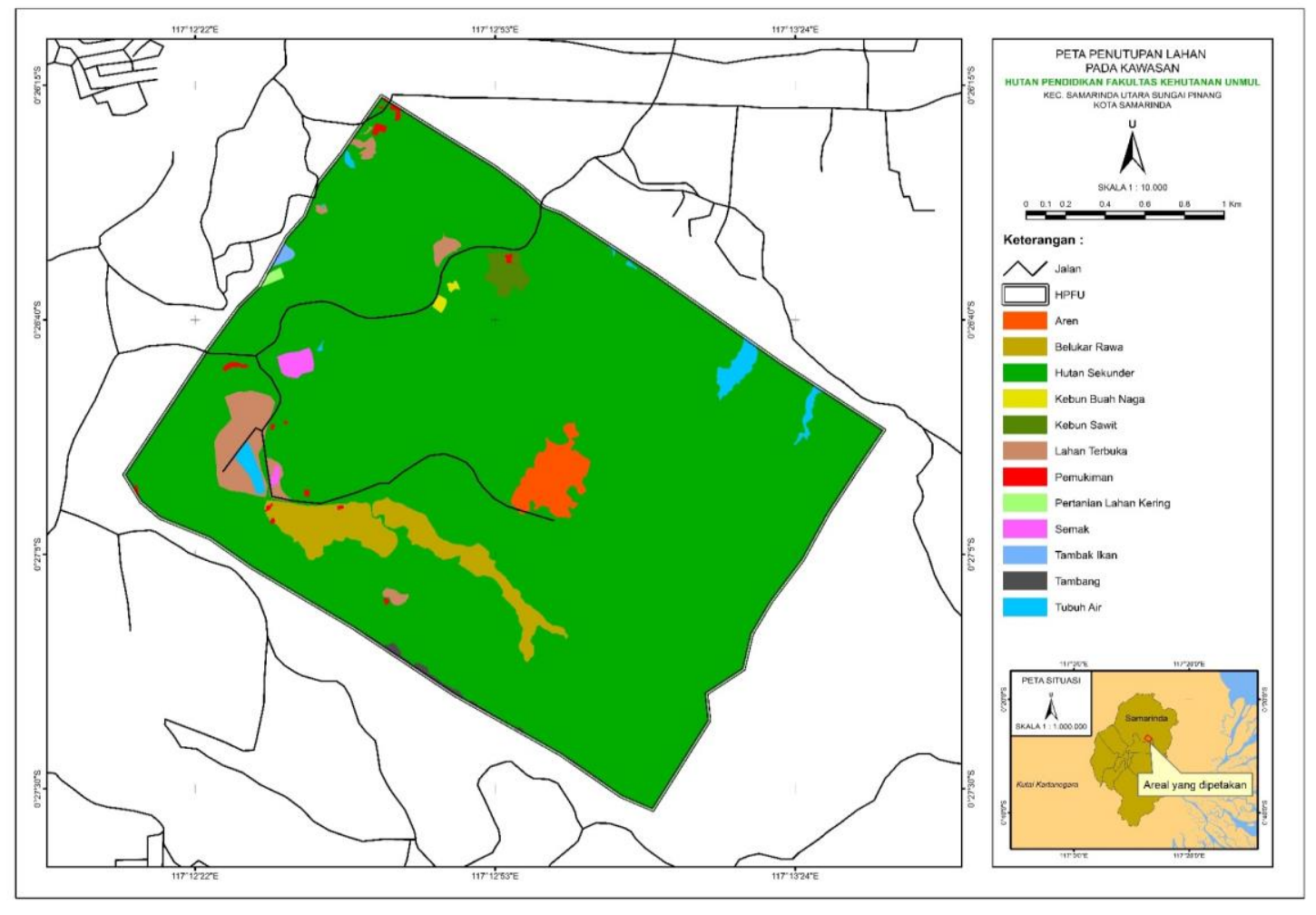

Gambar 4. Penggunaan Lahan pada Kawasan HPFU

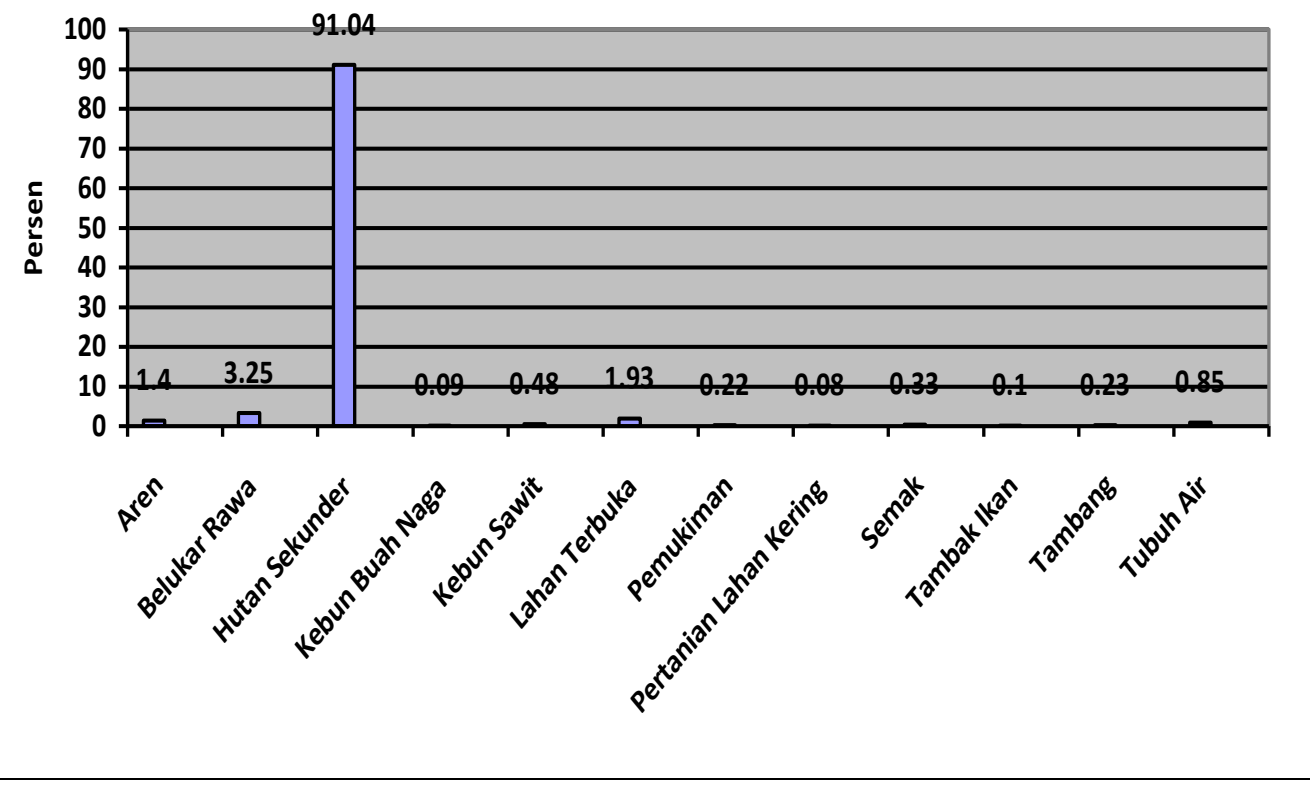

Gambar 5. Grafik Persentase Penggunaan Lahan pada Kawasan HPFU 
Tabel 2. Interpretasi citra foto udara pada Kawasan HPFU

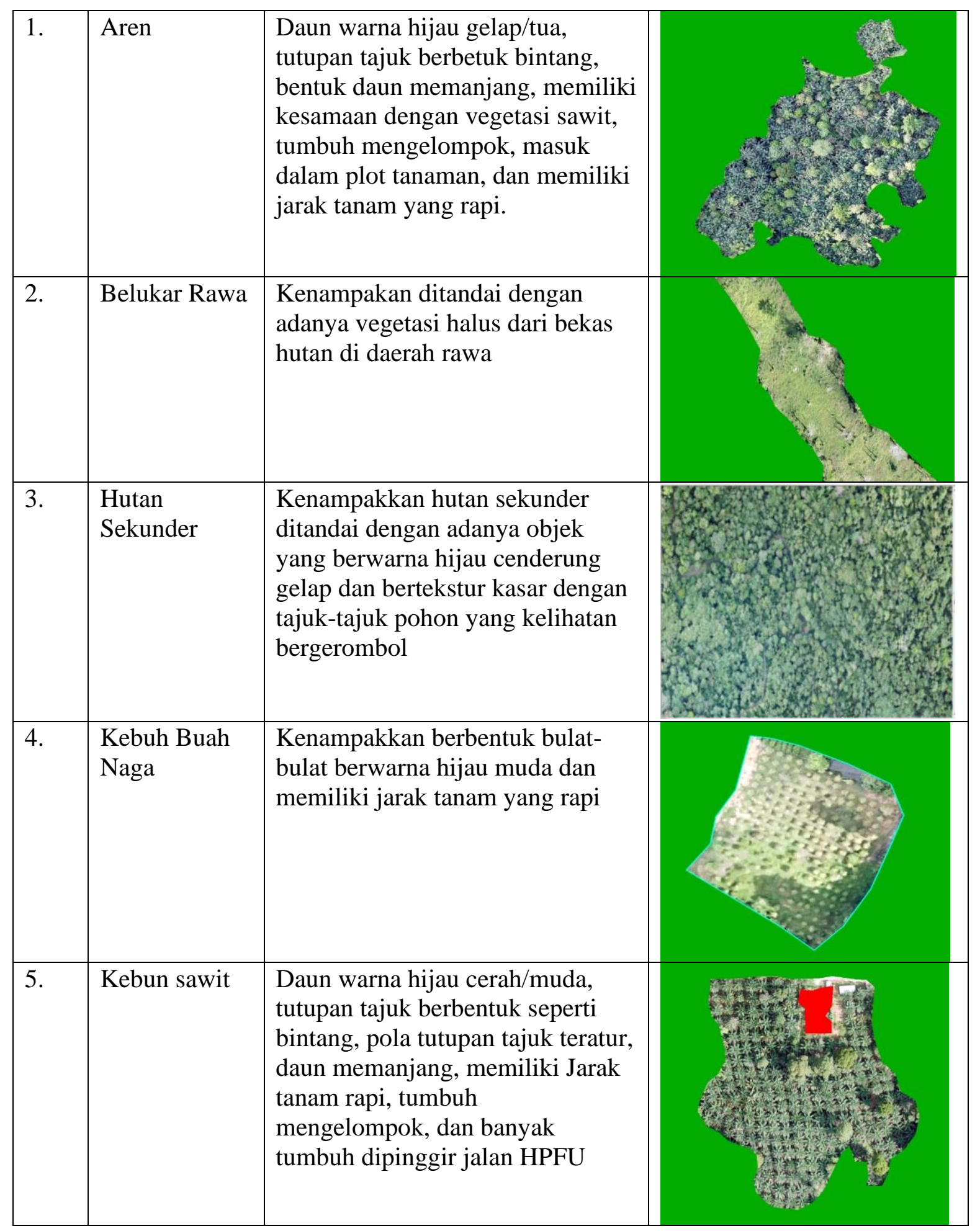




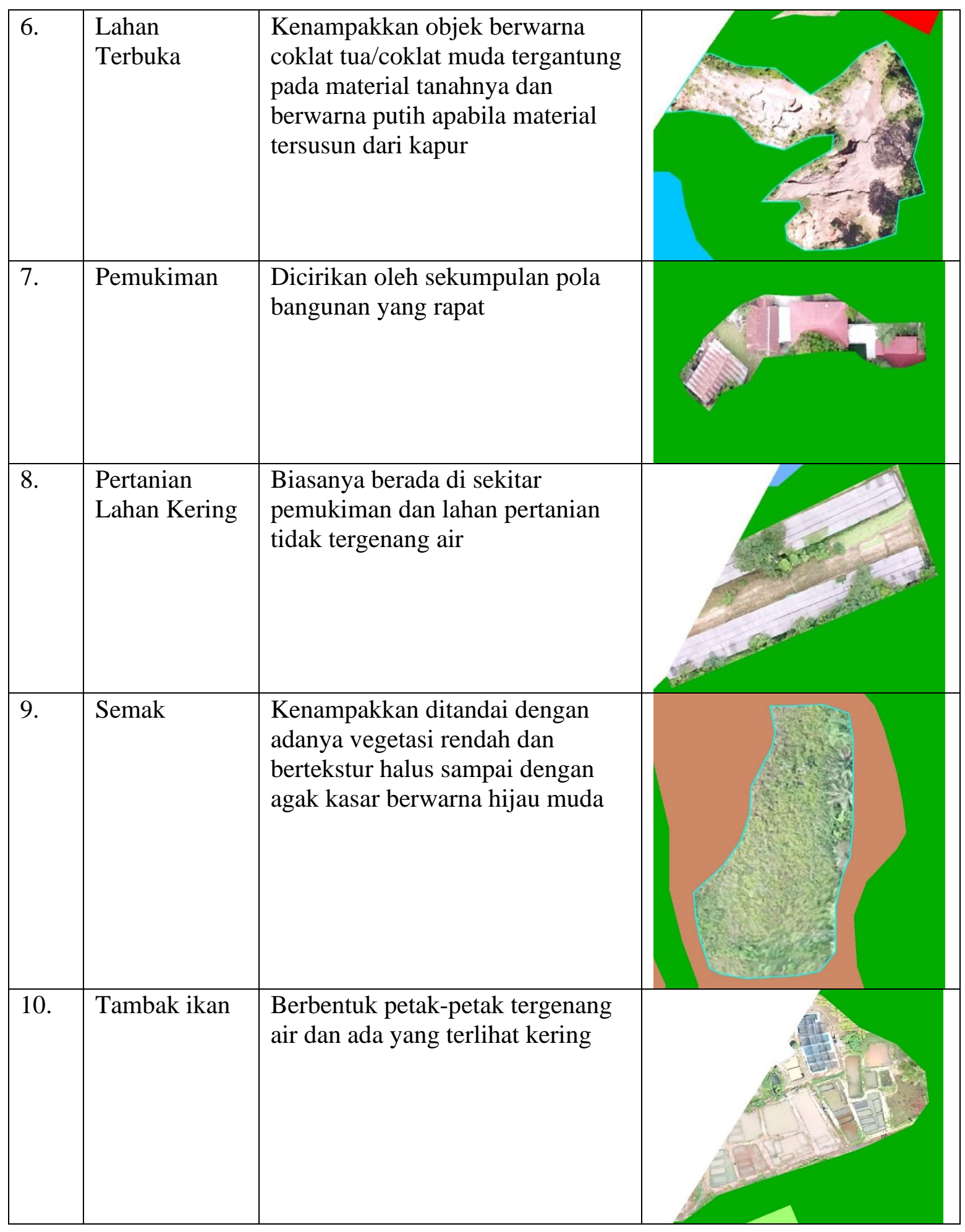




\begin{tabular}{|l|l|l|l|}
\hline 11. & Tambang & $\begin{array}{l}\text { Kenampakkan tambang seperti } \\
\text { tanah terbuka. Tambang ditandai } \\
\text { dengan adanya pola jaringan jalan } \\
\text { penghubung antar titik } \\
\text { pengemboran dan penimbunan }\end{array}$ \\
\hline 12. & Tubuh Air & $\begin{array}{l}\text { Kenampakkan terlihat ditandai } \\
\text { dengan adanya areal berwana } \\
\text { coklat berupa genangan air }\end{array}$ & \begin{tabular}{c} 
(a) \\
\hline
\end{tabular} \\
\hline
\end{tabular}

\section{KESIMPULAN}

Dari pembahasan yang dilakukan dapat diambil beberapa kesimpulan diantaranya sebagai berikut: Pengolahan foto-foto menjadi orthophoto dilakukan dengan menggunakan perangkat lunak Agisoft Photoscan. Dari hasil 949 pemotretan foto udara pada Kawasan HPFU, Untuk perangkat lunak Agisoft Photoscan waktu untuk pembentukan orthophoto diperlukan waktu \pm 2 jam pada tingkat akurasi medium. Dan menghasilkan orthophoto yang cukup baik.

Berdasarkan hasil interpretasi melalui foto udara pada kawasan HPFU untuk penggunaan lahan didapatkan 12 jenis penggunaan lahan dan tutupan lahan. Hutan Pendidikan Fakultas Kehutanan (>90 \%) terdiri dari Hutan sekunder dengan luas 269,36 ha, disusul oleh Belukar rawa 9,62 ha, Lahan terbuka 5,75 ha, Aren 4,13 ha, Tubuh Air 2,51 ha, Kebun Sawit 1,41 ha, Semak 0,98 ha, Tambang 0,68, Pemukiman 0,64 ha,
Tambak Ikan 0,30 ha, Kebun Buah Naga 0,26 ha dan Pertanian Lahan Kering 0,23 ha.

\section{DAFTAR PUSTAKA}

Admoko, D. (2015). Kajian Pembuatan Dem Menggunakan Perangkat Lunak Agisoft Dan Pix4dmapper Dari Data Pemotretan UAV (Studi Kasus: Desa Gading KulonKecamatan Dau Kabupaten Malang Jawa Timur) (Doctoral dissertation, Institut Teknologi Nasional Malang).

Bintoro, W., Oktorini, Y., \& Darli, V. V. (2018). PEMETAAN DETAIL TUTUPAN LAHAN MENGGUNAKAN PESAWAT TANPA AWAK DI ARBORETUM UNIVERSITAS RIAU DAN SEKITARNYA. JURNAL ILMU-ILMU KEHUTANAN, 2(1), 15-25. 
Julzarika, A. (2010). Perbandingan Teknik Orthorektifikasi Citra Satelit SPOT5 Wilayah Semarang dengan Metode Digital Mono Plotting (DMP) dan Metode Rational Polynomial Coefficients (RPCs). Jurnal Penginderaan Jauh dan Pengolahan Data Citra Digital, 6.

Junarto, R., Djurjani, D., Permadi, F. B., Ferdiansyah, D., Admaja, P. K., Sholikin, A. R., \& Rahmansani, R. (2020). Pemanfaatan teknologi unmanned aerial vehicle (uav) untuk pemetaan kadaster. BHUMI: Jurnal Agraria dan Pertanahan, 6(1).

Karyati, K., \& Syafrudin, M. (2016). Fluktuasi iklim mikro di Hutan Pendidikan Fakultas Kehutanan Universitas Mulawarman.

Karyati, K., \& Adhi, M. A. (2017). Jenisjenis Tumbuhan Bawah di Hutan Pendidikan Fakultas Kehutanan Universitas Mulawarman.

Lillesand, T. M., Kiefer, R. W., Dulbahri, Suharsono, P., Hartono, Suharyadi, \& Sutanto. (1993). Penginderaan jauh dan interpretasi citra. Gadjah Mada University.

Marwati, A., Prasetyo, Y., \& Suprayogi, A. (2018). ANALISIS PERBANDINGAN KLASIFIKASI TUTUPAN LAHAN KOMBINASI DATA POINT CLOUD LIDAR DAN FOTO UDARA BERBASIS METODE SEGMENTASI DAN SUPERVISED. Jurnal Geodesi Undip, 7(1), 36-45.
Sari, N. M., \& Kushardono, D. (2014). Klasifikasi Penutup Lahan Berbasis Obyek Pada Data Foto Uav Untuk Mendukung Penyediaan Informasi Penginderaan Jauh Skala Rinci (Object Based Classification Of Land Cover On Uav Photo Data To Support The Provision Of DetailedScale Remote Sensing Information). Jurnal Penginderaan Jauh dan Pengolahan Data Citra Digital, 11(2).

Schmidt, F. H. (1951). Rainfall types based on wet and dry period ratios for Indonesia with western New Guinee. Verhandelingen.

Sitompul, J. R., Ruswanti, C. D., Sukandar, H., Ganesa, A. S., Pratama, F. R., Siagian, H. S., \& Pribadi, R (2019). Klasifikasi Vegetasi dan Tutupan Lahan Pada Citra UAV Menggunakan Metode Object-Based Image Analysis di Segara Anakan, Kabupaten Cilacap.

Swastikayana, I. (2011). sistem informasi geografis berbasis web untuk Pemetaan pariwisata kabupaten gianyar (studi kasus pada dinas Pariwisata kabupaten gianyar) (Doctoral dissertation, UPN" Veteran" Yogyakarta).

Radiansyah, S. (2017). Aplikasi Pesawat Tanpa Awak (UAV)/Drone untuk Pemantauan Satwa Liar. Scientific Repository, 1-77.

Hodgson, J. C., Baylis, S. M., Mott, R., Herrod, A., \& Clarke, R. H. (2016). Precision wildlife monitoring using unmanned aerial vehicles. Scientific reports, 6(1), 1-7. 
Paneque-Gálvez, J., McCall, M. K., LUAS TUTUPAN LAHAN Napoletano, B. M., Wich, S. A., \& MENGGUNAKAN UAV Koh, L. P. (2014). Small drones for community-based forest monitoring: An assessment of their feasibility and potential in tropical areas. Forests, 5(6), 1481-1507.

(Unmanned Aerial Vehicle) DI KAWASAN HUTAN DENGAN TUJUAN KHUSUS (KHDTK) ULM DI MANDIANGIN. Jurnal Sylva Scienteae, 3(5), 796-804.

Pranata, A. H., Jauhari, A., \& Fithria, A. (2020). ANALISIS AKURASI 